\title{
Editorial Responsibilities
}

(c) 2020. This is an Open Access article distributed under the terms of the Creative Commons-AttributionNoncommercial-Share Alike License 4.0 International (http://creativecommons.org/licenses/by-nc-sa/4.0/), which permits unrestricted use, distribution, and reproduction in any medium, provided the original work is properly attributed, not used for commercial purposes, and, if transformed, the resulting work is redistributed under the same or similar license to this one.

Editor-in-Chief: Lorie Kloda

Associate Editor (Evidence Summaries): Stephanie Krueger, Christina Wissinger

Associate Editor (Research Articles): Ann Medaille, Lisl Zach

Associate Editor (Classics \& Reviews): Jane Schmidt

Associate Editor (Commentaries, Using Evidence in Practice): Lorie Kloda

Communications Officer (News): Kimberly MacKenzie

Production Editor: Rachel Hinrichs

Editorial Intern: Melissa Cober

Editorial Advisors: Lindsay Alcock, Alison Brettle, Michelle Dunaway, Denise Koufogiannakis, Heather Pretty

Copyeditors: Heather Healy (Lead Copyeditor), Katelyn Baroody, Kirstin Duffin, Julie Evener, Emily Kingsland, Alison Moore, Jane Morgan-Daniel, Stacey L. Penney, Elizabeth Stregger, Nikki Tummon, Elaina Vitale, Ross Wilson

Indexing Support: Kate Shore

Editorial Assistant: Samantha Sheplawy 